\title{
Integração entre oficina de yogaterapia e oficina de intervenção psicossocial como ferramentas de apoio ao portador de diabetes mellitus em Tiradentes, Minas Gerais
}

Integration between a workshop on yogatherapy and a psychosocial intervention workshop as tools to support diabetes mellitus patients in the Tiradentes. State of Minas Gerais, Brazil

\section{RESUMO}

O diabetes é considerado uma síndrome metabólica. Ela vem acometendo um número cada vez mais significativo da população mundial. A realidade vivenciada em uma esfera macro náo é diferente no município de Tiradentes, Minas Gerais, comunidade em que se desenvolveram açóes no projeto de extensão que trabalhou questōes grupais e terapêuticas direcionadas aos diabéticos. Neste estudo, objetivou-se compreender a vivência da oficina de yogaterapia e da oficina de intervençáo psicossocial, como ferramentas complementares e incentivadoras para a adesão ao tratamento de um grupo de acometidos pelo Diabetes Mellitus nesta cidade. As técnicas foram utilizadas como uma proposta qualitativa com viés participativo, envolvendo 20 acometidos por esta condição de saúde. A metodologia participativa buscou valorizar o conhecimento prévio dos participantes em relaçáo ao diabetes Mellitus e seus cuidados, com perspectiva para envolver corpo e mente além de criar um espaço de reflexão, autorreflexão, autocuidado, respeito pelo outro, conhecimento corporal e fortalecimento diante de seus enfrentamentos. Nesta direção, entrevistas foram utilizadas para fomentar dados para análise. Por tais características pôde-se compreender como as açóes demonstram-se adequadas para os programas de educação em diabetes, isto indicado a partir das consideraçôes dos próprios participantes.

Palavras-chave: Oficina de yoga. Oficina de intervenção psicossocial. Educação continuada em diabetes Mellitus. Educação em saúde.

\begin{abstract}
Diabetes is considered a metabolic syndrome that has been affecting an increasingly significant number of the world's population. The reality experienced in a macro sphere is not different in the municipality of Tiradentes, State of Minas Gerais, Brazil, a community in which
\end{abstract}

Eva Vilma Muniz de Oliveira

Mestre em Psicologia pela Universidade Federal de São Joáo del-Rei, Minas Gerais, Brasil; professora do Instituto Federal de Ensino, Ciência e Tecnologia do Sudeste de Minas Gerais, campus São João del-Rei, Minas Gerais, Brasil.(eva. oliveira@ifsudestemg.edu.br).

Beatriz Domingues Perrella

Graduada em Psicologia pela Pontifícia Universidade Católica de Minas Gerais, Brasil (biaperrella@yahoo.com.br).

Marisângela Aparecida Resende

Técnica em Enfermagem pelo Instituto Federal de Ensino, Ciência e Tecnologia Sudeste de Minas Gerais, Campus São João del-Rei, Brasil (mariresende17@ gmail.com).

Jhéssica Lohâyne de Melo Gonzaga

Técnica em Enfermagem pelo Instituto Federal de Ensino, Ciência e Tecnologia Sudeste de Minas Gerais, Campus Sáo Joáo del-Rei, Brasil (jlohaynedemelogonzaga@gmail.com). 
actions were carried out in the Extension Project that worked on group and therapeutic issues directed to diabetics. This study aimed to understand the experience of the Yogatherapy Workshop and the Psychosocial Intervention Workshop as complementary tools and to promote treatment adherence of a group of patients affected by Diabetes Mellitus in this city. It used techniques as a qualitative proposal with participatory approach, involving 20 people affected by this health condition. The participatory methodology sought to value the participants' prior knowledge regarding diabetes mellitus and its care, with a perspective to involve body and mind creating a space for reflection, self-reflection, self-care, respect for others, body awareness and strengthening in face of their confrontations. In this direction, it used interviews to development data for analysis. By such characteristics it was possible to understand how such actions are adequate for health care education programs, this was indicated from the participants' own considerations.

Keywords: Yoga workshop. Psychosocial intervention workshop. Continuing education in diabetes Mellitus. Health care education.

\section{INTRODUÇÃO}

Em geral, as doenças crônicas estão relacionadas a causas múltiplas, são caracterizadas por início gradual, de prognóstico usualmente incerto, com longa ou indefinida duraçáo. Apresentam curso clínico que muda ao longo do tempo, com possíveis períodos de agudização, podendo gerar incapacidades. Requerem intervençóes com o uso de tecnologias, associadas a mudanças de estilo de vida, em um processo de cuidado contínuo que nem sempre leva à cura (BRASIL, 2013).

No caso da Diabetes, de acordo com Oliveira, Montenegro Junior e Vencio (2018), são três os tipos mais comuns: diabetes Mellitus tipos 1 (DM1), diabetes Mellitus tipo 2 (DM2), e diabetes gestacional (DMG).

O Diabetes Mellitus (DM) consiste em um distúrbio metabólico caracterizado por hiperglicemia persistente, decorrente de deficiência na produção de insulina ou na sua ação, ou em ambos os mecanismos, ocasionando complicaçóes em longo prazo (IDF, 2017). Em relação ao tratamento, Rezende (2017) ressalta que apenas o tratamento 
medicamentoso náo é suficiente para manter a saúde e o controle da doença, sendo de extrema importância a abordagem terapêutica associada ao processo de educação em saúde, estes, fundamentais para a prevenção de complicaçóes e para a manutenção da qualidade de vida.

Segundo dados da IDF (2017), 425 milhóes de pessoas vivem com $\mathrm{DM}$, sendo os países de baixa e média renda os que possuem em torno de $80 \%$ desses portadores da doença. Nesse sentido, o Brasil ocupa o $4^{\circ}$ lugar entre os 10 países com maior número de indivíduos com diabetes, chegando a 12,5 milhóes de acometidos, com prevalência de 8 a 9\% da populaçáo. É, ainda, o $6^{\circ}$ país do mundo em gastos com o DM e permanece em $3^{\circ}$ lugar em relação ao maior número de diabéticos Tipo I, crianças e adolescentes menores de 20 anos, estando em torno de 88.300 acometidos pelo distúrbio, ficando atrás somente dos Estados Unidos, com 169.900, e da Índia com 128.500 de diabéticos.

A Associação Protetora dos Diabéticos de Portugal (APDP) destaca que a adesão ao tratamento difere em relação à idade, ao gênero e à experiência de vida de cada indivíduo. Contudo, é uma das maiores dificuldades pela qual a pessoa com diabetes se depara no convívio com a doença, pois implica mudanças em nível da rotina familiar e pessoal (APDP, 2015). Nesse sentido, essas açôes e o modo como cada sujeito realiza seu controle e seu acompanhamento diário influencia na percepção que o outro possui, estabelecendo um espaço de reflexão e aprendizagem.

Diante desse cenário, a cidade escolhida para o presente estudo foi Tiradentes-MG, uma vez que ter sido alvo de estudos anteriores relacionadas ao público diabético e carecer de intervençôes e estudos nessa área, conforme identificaçáo de número restrito de trabalhos que tratam o assunto. Sendo assim, utilizou-se de intervençóes em oficinas de yogaterapia $(\mathrm{OU})$ e de oficinas de intervenção psicossocial (OIP) como ferramentas de suporte ao tratamento em um grupo de acometidos pelo diabetes nesse município.

Como pressuposto de estruturaçáo, utilizou-se da yogaterapia que começa a ser difundida como uma linha terapêutica que emprega as diversas ferramentas do yoga no cuidado e tratamento de várias condiçôes de saúde, portanto, é considerada uma prática integrativa 
que reúne aspectos físicos, energéticos, emocionais e espirituais. Dentre as ferramentas utilizadas, destacam-se os ásanas (posturas psicofísicas), pranayamas (exercícios respiratórios), relaxamento e meditação.

Num segundo momento, lançou-se mão da intervenção psicossocial, práxis da psicologia social, que nasce interdisciplinar e aborda processos de transformação em contextos sociais diversos, a partir da análise crítica das estruturas e das relaçôes sociais, do cotidiano, das instituiçóes, da escuta qualificada e do trabalho com os sujeitos individuais ou coletivos, suas crises, demandas e projetos (AFONSO; FADUL, 2015). Ambas as técnicas foram articuladas pelo viés interdisciplinar, diante da configuração da equipe do projeto, constituída por enfermeira, psicóloga e alunas do curso técnico em enfermagem.

Neste sentido, o presente estudo objetivou compreender a vivência dessas oficinas como ferramentas complementares e incentivadoras para a adesão ao tratamento de acometidos pelo DM na cidade de Tiradentes-MG.

Nesta esfera, por meio da realização de OU e OIP, assuntos diversos foram abordados, possibilitando açóes direcionadas aos participantes assistidos. Dessa forma, as ações desempenhadas ganharam importância nesse contexto, uma vez que essa alternativa pôde trazer benefícios para a condução do tratamento dos portadores de DM do município estudado, isto, conforme própria indicação dos participantes.

Por meio da vivência junto ao grupo acompanhado, pode-se identificar o fomento a aspectos que contribuíssem para a compreensão da realidade desse público. Constataram-se as dificuldades enfrentadas pelos diabéticos diante dessa realidade, entendendo-se que as açôes educativas devem ser um processo contínuo, não estanque, voltado para o apoio e a educação continuada. Verificou-se, ainda, a existência de elementos que podem ter influenciado a forma com que os participantes percebem e vivenciam o diabetes, tais como aspectos culturais, sociais e emocionais, além do apoio que a rede de assistência em saúde oferta. Dessa forma, pode-se perceber que a participaçáo nas OY e OIP favoreceram tanto a partilha de informaçóes técnicas, como de concepçóes afetivo-emocionais acerca do enfrentamento da doença, se conhecer e conhecer seu próprio corpo, suas limitaçóes 
e expansóes, subsidiando, assim, uma nova forma de se perceber perante o diabetes.

\section{Aspectos referenciais}

O Ministério da Saúde reconhece e incentiva, desde 2006, as PIC (Práticas Integrativas e Complementares), sendo que, em 2011, o yoga e outras terapias complementares foram incluídas no Sistema Único de Saúde (SUS) a partir da criação do Programa Academia de Saúde (Portaria no 719, de 7 de abril de 2011). Esse posicionamento indica uma abertura para uma visão mais ampla e integrada do processo saúde/doença, além de um alinhamento com diretrizes da Organização Mundial de Saúde (OMS).

McCall (2007) descreve que a yogaterapia apresenta açáo positiva diante das seguintes condições de saúde: artrite, asma, dor lombar, câncer, síndrome do túnel carpal, síndrome da fadiga crônica, depressão, diabetes, fibromialgia, cefaleia, problemas cardíacos, pressão alta, HIV/Aids, infertilidade, insônia, síndrome do intestino irritável, menopausa, esclerose múltipla, aumento de peso e obesidade.

As atividades grupais podem ser positivas e aliviar dificuldades advindas da doença por meio de benefícios como a vivência e conhecimento a partir da experiência partilhada entre outros portadores da doença. Segundo Oliveira et al. (2016), ao fazer parte de um grupo, os participantes desenvolvem vínculos e identificaçôes entre os membros, auxiliando na ressignificação de experiências. $\mathrm{O}$ acometido pelo diabetes encontra nesse grupo de pessoas, que têm experiências semelhantes às suas, vivências e saberes que podem apresentar soluçóes para as situaçóes geradoras de ansiedade.

Essas atividades grupais planejadas e organizadas de modo participativo são açóes que têm potencial de propiciar a assimilação de conhecimentos e desenvolver habilidades, atitudes e comportamentos para o manejo com a doença. Compreende-se que esse é um caminho construtivo e longo para que o diabético obtenha um espaço de escuta que lhe oferte estímulo pelo conhecimento sobre a sua doença, apoio para sua aceitação e que forneça instrumentos para o autocuidado (OLIVEIRA et al., 2016). 
A Oficina possui dois pilares de ação: (a) a potencialidade terapêutica, já que facilita o insight e a elaboração sobre questóes subjetivas, interpessoais e sociais; e (b) a potencialidade pedagógica, em que deslancha um processo de aprendizagem, a partir da reflexão sobre a experiência. Ela é capaz, portanto, de permitir ao sujeito elaborar o conhecimento sobre o mundo e sobre ser no mundo, ou seja, sobre si mesmo. A elaboração produzida na Oficina envolve, além de uma reflexão racional, os sujeitos de uma maneira geral, suas formas de pensar, sentir e agir (AFONSO, 2006).

Portanto, vale ressaltar que, para Menezes e Avelino (2016), é indispensável que os profissionais da saúde discutam e aprendam sobre os fenômenos grupais, pois a organização desses grupos como modalidade de atenção coletiva é cada vez mais necessária no Sistema de Saúde, principalmente como prática educativa e preventiva na Atenção Primária.

\section{METODOLOGIA}

No desenho do percurso metodológico deste trabalho, optou-se pela utilização de métodos qualitativos com viés participativo com a utilização de OY e OIP direcionadas aos acometidos pelo DM na cidade de Tiradentes/MG, por meio das açóes desempenhadas no projeto de extensão, inscrito no Edital 07/2018 - IF Sudeste MG/ Campus São João del Rei.

No primeiro e no último dia das oficinas foram realizadas conversas breves e direcionadas (entrevistas) com todos os participantes. Essa ação teve como propósito conhecer realidades e necessidades e, posteriormente, comparar as respostas e verificar como as açóes estabelecidas, segundo a percepçáo dos participantes, proporcionariam melhorias na condução do seu tratamento. Com tais informaçôes coletadas, bem como todo o processo vivencial das oficinas atrelado às observações dos participantes subsidiaram a análise do projeto e seus resultados.

Afonso, (2006), ressalta que a Oficina tem uma dimensão ou potencialidade terapêutica, na medida em que facilita o insight e a elaboração sobre questóes subjetivas, interpessoais e sociais. Também 
tem uma dimensão ou potencialidade pedagógica, na medida em que deslancha um processo de aprendizagem, a partir da reflexáo sobre a experiência. Nesse sentido, objetivou-se vivenciar a OY e a OIP como ferramentas complementares e incentivadoras para a adesão ao tratamento de acometidos pelo DM na cidade de TiradentesMG. Em termos éticos, os cuidados apregoados pela condução dos trabalhos dessa natureza foram executados. Entretanto, por se tratar de um estudo considerado de riscos mínimos ou inexistentes, isto posto que sua proposta é de cunho dialógico e, por se tratar de um projeto de extensão, optou-se pela não apresentação da demanda às instâncias de avaliação.

Os critérios de inclusão para a participação do projeto foram: a) pessoas com idade acima de 18 anos, b) moradores da cidade pesquisada e c) pessoas em busca de alternativas de apoio no tratamento que náo somente se referem aos cuidados biomédicos. E os critérios de exclusão se direcionaram a: a) pessoas acamadas ou com dificuldade extrema de deslocamento até o local das atividades e b) não adeptos às práticas alternativas que possam apoiar o portador diante dos cuidados.

Para a formação dos grupos, a Secretaria de Saúde Municipal disponibilizou uma lista com nomes de diabéticos da cidade, sendo escolhida, portanto, a micro área 01 , estando ela geograficamente mais próxima ao local em que foram desenvolvidas as atividades grupais. Em seguida as duas bolsistas do projeto visitaram juntamente com a ACS (Agentes Comunitários de Saúde) desta área, as residências dos diabéticos para fazer o convite para a participação dos grupos.

Decidiu-se pela divisão em dois grupos, para o acompanhamento de 12 semanas, fosse na residência ou grupal. $O$ primeiro não participaria das Oficinas, mas seria acompanhado semanalmente pela equipe do projeto. Com todos os participantes foram realizados controle glicêmico, aferição de pressão arterial, frequência cardíaca, oximetria, medida de circunferência abdominal e cálculo de IMC (Índice de Massa Corpórea). Com o primeiro grupo, para avaliação dos dados descritos acima, foram realizados acompanhamentos domiciliares semanais pela equipe do projeto, bem como, orientaçóes e prevençáo de complicaçóes advindas dessa síndrome metabólica. $\mathrm{O}$ segundo grupo foi convidado a participar de intervençóes grupais em encontros semanais. Os participantes convidados puderam optar por qual 
acompanhamento gostariam de se dedicar, se individual ou grupal. Assim, foram constituídos os grupos do projeto de forma aleatória. Estabelecendo-se, portanto, 12 encontros, sendo 8 destinados às OY e 4 para as OIP, concomitantemente aos 12 acompanhamentos domiciliares.

As etapas do processo de oficinas foram definidas e a elaborou-se conjuntamente um "contrato": um compromisso feito verbalmente entre os agentes internos e externos sobre as regras de funcionamento do grupo, os deveres e direitos de cada membro. Nesse "contrato", combinou-se o número de encontros, local de realização dos encontros, horário, materiais a serem utilizados e o papel dos participantes e coordenadores do grupo.

Para a construção de cada etapa das oficinas, utilizou-se a abordagem dialógica, a valorização do conhecimento dos sujeitos, os recursos e as estratégias pedagógicas em que o saber técnico-científico se depara com a realidade vivenciada e experienciada. Cada participante foi respeitado em suas opinióes e foi valorizada, nos debates, a sua capacidade de enfrentamento da doença e as possibilidades das açôes de autocuidado. A cada encontro, foi estimulada a autonomia dos participantes (FREIRE, 1996).

Nesse sentido, a Yogaterapia foi desenvolvida a partir da linha de yoga conhecida como Hatha-Yoga. O Hatha-Yoga é uma vertente do yoga que busca desenvolver o potencial do corpo estabelecendo sua integração com a mente, atenuando, desta forma, problemas físicos e emocionais. Trata-se da ramificação do yoga mais difundida no Ocidente, cujo sistema é composto por posturas corporais, controle da respiração, inibição sensorial, concentração e meditação, além de diversas técnicas de limpeza orgânica (BERNARDI et al., 2013).

No caso das OIP, entende-se que não se trata de definir qual é a "mudança certa" para um dado grupo social e sim de construir com ele as possibilidades de transformação que ampliam e desenvolvem a sua autonomia (AFONSO, 2011).

\section{RESULTADOS E DISCUSSÃO}

Pensando em articular as dimensóes de uma oficina nos espaços 
destinados às reflexôes, às elaboraçóes de vivências e aos diálogos atrelados às experiências do outro, construiu-se as intervençóes junto ao grupo de acometidos pela DM. Para tanto, a palavra circulou e tomou forma, sendo possível aprender, escutar e refletir sobre novos posicionamentos frente às suas experiências semanais com as atividades propostas, suas dificuldades e as potencialidades adquiridas no contexto do ser diabético.

Para a construção de cada etapa das oficinas, foram utilizados a abordagem dialógica, a valorizaçáo do conhecimento dos sujeitos, os recursos e as estratégias pedagógicas baseadas no trabalho grupal.

As OY foram estruturadas de forma a respeitar as condiçóes físicas dos participantes, gradualmente sendo inseridas posturas físicas (ásanas) e exercícios respiratórios (pranayamas) de maior complexidade, com o objetivo de se chegar às posturas que têm potencialmente maiores benefícios para o diabético. Isso, de acordo com os autores referidos e outros que também desenvolveram pesquisas na área, a saber: Iyengar (2016), Hermógenes (2014), Brandha e Saraswati (2009).

Já as OIP foram baseadas no processo grupal como ferramenta para reflexão e autoreflexão entre os sujeitos participantes, entendendo que o saber técnico-científico se depara com a realidade vivenciada e experienciada. Diante deste contexto, estabeleceram-se três caminhos a serem direcionados para as questóes que abarcam o autocuidado diante do diabetes, são eles, os pilares de cuidados: dieta, medicação e exercício físico, com foco no aprendizado em via de mão dupla, na autonomia e no autogerenciamento dos sujeitos.

Em relação ao público participante do projeto, identificou-se que $80 \%$ eram do sexo feminino. A média de idade girou em torno dos 53 anos. A média de idade do público masculino se mostrou superior, sendo de 62 anos.

Deste modo, as oficinas (grupo 1) foram programadas com tempo de contato de 2 horas em cada encontro, nas quais a média de participação foi de 10 a 12 usuários. Os acompanhamentos domiciliares (grupo 2) obtiveram um tempo médio de duração de 30 minutos, com acompanhamento de 10 a 7 residências/semana.

Ressalta-se, portanto que o grupo 2, inicialmente formado por 10 
integrantes, passa a ser composto por sete, em que um deles recebeu três acompanhamentos domiciliares da equipe, porém na $4^{\mathrm{a}}, 5^{\mathrm{a}} \mathrm{e}$ $6^{a}$ não foi encontrado em sua residência, fato comunicado à ACS do bairro, para posterior acompanhamento médico. Os outros dois participantes, um casal, se mudaram da cidade, porém foram acompanhados até a sétima visita.

Nos dois grupos formados, tanto o grupo de intervençóes (1) ou de acompanhamento domiciliar (2), o perfil dos participantes foi marcado predominantemente por idosos, sendo eles acometidos pelo diabetes Tipo I e II. O grupo 1 foi formado por dois diabéticos Tipo I e oito diabéticos Tipo II, já o grupo 2 foi composto por um diabético Tipo I e nove diabéticos Tipo II.

Notou-se que, além da DM, essas pessoas também são acometidas por outras condições de saúde, e o uso de polifármacos faz parte do seu cotidiano, sendo eles, hipoglicemiantes orais e insulinas, anti-hipertensivos, antiarrítmicos, antidepressivos, corticóides, polivitamínicos, repositores hormonais, hormônio tireoideano, estatinas, anticoagulantes, antipsicóticos e inibidores da hidroximetilglutarilcoenzima A (HMG-CoA) redutase, dentre outros.

Em relação aos parâmetros analisados semanalmente, pôde-se compreender que no grupo 2 , se obteve quatro 4 casos de diabéticos acompanhados que se destacaram significativamente nessas 12 visitas, isto, da primeira para a última visita.

No primeiro caso, no quesito glicemia capilar, em que o acometido apresentou um valor de $270 \mathrm{mg} / \mathrm{dl}$ e conseguiu evoluir para $152 \mathrm{mg} /$ $\mathrm{dl}$; no segundo, a acometida colocou como meta eliminar peso, inicialmente com $80,3 \mathrm{~kg}$ foi alcançado o estabelecido de $76,9 \mathrm{~kg}$. Em relação à frequência cardíaca $(\mathrm{FC})$, houve um destaque em que a diabética apresentou bradicardia em sete visitas, sendo assim solicitado acompanhamento médico com posterior reavaliação das medicações; havendo uma melhoria da FC de $48 \mathrm{bpm}$ para $67 \mathrm{bpm}$. E por último, uma participante apresentou seus parâmetros de avaliação, especificamente pressão arterial, frequência cardíaca, oximetria, glicemia capilar, peso e IMC, exceto circunferência abdominal, dentro dos valores considerados normais em todas as visitas, mesmo não se exercitando e nem seguindo dieta, fato que pode estar relacionado ao metabolismo individual. 
Diante desse cenário, entendeu-se ainda que esse acompanhamento semanal trouxe aos participantes os sentimentos de valorização, cumplicidade, parceria e confidencialidade, no sentido de compartilhar seus anseios em relação ao diabetes, bem como refletir sobre sua condiçáo de saúde e ter na equipe um apoiador no seu tratamento.

Antes de iniciar as oficinas e as visitas, foram estabelecidos quatro questionamentos, a fim de conhecer a realidade desse participante: a) Como o participante considera seu estado de saúde; b) Se está em acompanhamento psicológico; c) Se pratica algum tipo de exercícios físico e d) Como são seus hábitos alimentares.

A partir das respostas obtidas, pensou-se sobre como incentivá-los a refletir sobre si e sua condição de saúde. Inicialmente os participantes se consideravam pouco saudáveis e, no decorrer, foi-se construindo o entendimento que essa não é uma condição que os impossibilita de viver e se sentirem saudáveis, uma vez que, ter saúde depende deles próprios. Nenhum dos acometidos experienciou, ainda, o acompanhamento psicológico, fato este, de extrema relevância, pois, esta condição de saúde produz sentimentos e sensações inexploradas. Em relação ao exercício físico, aqueles que praticam fazem caminhada como estratégia para atender aos cuidados propostos pelo diabetes. Eles, após as açôes, foram despertos para iniciar exercícios ou até mesmo conhecer outros tipos. Finalmente, em relação a seguir dieta, percebeu-se que ainda é, para a maioria, algo dificultoso que foi sendo aprimorado e experimentado pelo grupo, com partilhadas, trocas, dedicação e a necessidade da educação continuada.

Em busca de sigilo, ética e preservaçáo de suas identidades, os participantes dessa pesquisa receberam nomes fictícios, conforme apregoa a correta conduçáo de estudos com seres humanos, tendo sido o projeto aprovado pelo Comitê de Ética em Pesquisa com apresentação de Termo de Consentimento Livre e Esclarecido.

Para a análise da relação nesses dois contextos, fossem oficinas ou visitas, estabeleceu-se a confecção dos relatos dividindo-os em quatro categorias temáticas, sendo: 1. Reflexão psicossocial; 2. Reflexão corpórea; 3. O processo de elaboraçáo do autocuidado; 4. A relação educação e saúde em diabetes. Compreendeu-se que esses aspectos estiveram presentes nessas propostas proporcionando aos sujeitos reflexôes grupais, individuais, além de ressignificaçôes com falas 
condizentes ao reconhecimento de si no outro; o conhecimento de seu corpo e suas possibilidades de expansão; o cuidado voltado para si e para seus enfrentamentos e as dimensóes do processo de educaçáo continuada em diabetes.

\section{Reflexão psicossocial}

A primeira categoria, nomeada como reflexão psicossocial, surgiu da necessidade de compreender o sujeito diabético não somente com suas questôes biomédicas e o padrão estabelecido para o sucesso do seu tratamento, mas também para o entendimento dos aspectos psicossociais a que estão inseridos em seu cotidiano, isto, ao vivenciar e experienciar suas relaçóes grupais.

Os processos de pensar, sentir e agir se tornaram ferramentas necessárias nessa vivência do ser e do estar diabético. Perpassando pelos aspectos psicossociais, que envolvem reflexóes e autorreflexóes, esses participantes puderam experienciar esses sentimentos, ora individualmente, ora no âmbito familiar, ora coletivamente. Importante ressaltar que esse ponto de vista depende do contexto em que estão inseridos e da forma que se veem diante de sua condição de saúde. Os dizeres abaixo exemplificam:

Lívia - eu me autoconheci, estou uma pessoa mais calma, mais tranquila, uma pessoa que está sabendo mais ouvir e interpretar as coisas.

Antônio - isso aqui (apontando para o círculo) me fez ficar pensando um monte de coisa....

Lia - quando eu tô aqui não quero pensar em mais nada, esse momento é meu....

Entendeu-se que as oficinas possibilitaram momentos para demonstrar os sentimentos alocados nesse público, suas diversas maneiras de expressar histórias de vida, suas crenças, seus hábitos, sua rotina diária, suas reflexóes e sentimentos, propiciando, dessa forma, um espaço de escuta, observação e aproximação entre pares.

Foi possível observar que ao realizar as OY, esses participantes chegavam 
eufóricos e conseguiam conduzir essas sensaçôes na roda de conversa para concentração inicial, em que todos tinham oportunidade de dizer sobre sua semana e em seguida a prática de yoga proporcionavam tranquilidade e serenidade. Diferentemente dessa experiência, as OIP fizeram com que os participantes pudessem expressar seus anseios durante todo o processo, por meio de questionamentos, experiências partilhadas, ensinamentos e aprendizados, ou seja, momentos e propostas diferentes de se trabalhar a escuta e a fala individual e em grupo. Já nos acompanhamentos domiciliares, os espaços de expressão foram por vezes individualizados sendo estabelecidos os vínculos de cumplicidade e confidencialidade.

Mariano - às vezes nós estamos assim aflitos pra falar e vocês estáo ali ouvindo e falando, dá atenção e a gente aprende também. (dizendo da experiência com a OY)

Márcia - aqui a gente tá aprendendo a cuidar melhor da nossa saúde e do diabetes... ai fica querendo falar e saber das coisas... (risos). (dizendo da experiência da OIP)

Clarice - Melhorei muito, quando vocês chegou aqui eu estava um "caco", agora graças a Deus eu tenho animação pra trabalhar... (dizendo da experiência com as visitas)

As três propostas estabelecidas nos mostraram que são elas formas de auxílio em busca de melhor adesão ao acometidos, isto, nos diversos contextos a que estão inseridos, seus enfrentamentos, as variadas formas de se ver e estar diante desta condição de saúde, o diabetes.

Compreender o outro e se colocar no lugar do outro também se tornou um trabalho de promoção, proteção e prevenção educativa em diabetes que foi sendo sistematizado nessas propostas de trabalho. As características que os acometidos têm em comum estão direcionadas a um apoio psicossocial, o que os conduz a desenvolver suas estratégias conhecendo suas limitações, disponibilidades, anseios, habilidades, interesses, enfim, aspectos que podem trazer assimilaçóes consideradas 
por eles úteis no seu cotidiano. O que é notado a seguir:

Mariano - Muito me ajudou porque vocês são as que param e escutam e isso vai enriquecendo, fortalecendo o dia a dia, em outros grupos que já passei chegava lá e não tinha isso, chegava lá e pensava vou lá pra quê se não tenho direito de voz... aí largava pra lá.

Lívia - foi muito especial porque a gente que é diabético somos carentes, a saúde da gente é debilitada de certa forma então a gente tem uma certa carência... e aqui acolhem a gente, sempre com uma palavra bacana...

Esses relatos reforçam que, ao desenvolver uma pesquisa sob a ótica humanística, construiu-se uma perspectiva psicossocial, a qual provoca a elaboração de intervençóes voltadas para a realidade objetiva e subjetiva de cada sujeito para, entáo, atender suas reais necessidades. Sendo assim, a escuta e a troca de informaçóes entre os participantes foram aspectos fundamentais nesse processo.

Assim, tornou-se de extrema relevância trabalhar os aspectos do empoderamento diante da $\mathrm{DM}$, fato que traz consigo a construção do autoconhecimento e autogerenciamento, as formas de conservaçáo e condução do seu tratamento, bem como as formas de facilitar o sucesso no tratamento. Estar em grupo vale-se de se reconhecer no outro, além do ensinar e aprender, trabalhando em uma via de mão dupla, conforme descrito abaixo:

Bruno - eu tentei passar alguma coisa que eu sei pra vocês, que eu sei que acontece comigo [...], você tem que cuidar de você, se conhecer.

Lia - todo mundo que ajudou a gente aqui, principalmente o Bruno que tá sempre orientando [...] eu tô muito mais feliz depois que comecei aqui.

As dimensôes que as intervençôes grupais propiciaram aos diabéticos foram capazes de manifestar aspectos condizentes às reflexóes grupais 
e individuais, bem como favorecer a criação de vínculos, identificações e afirmaçóes de si mesmo no outro. Estes são aspectos elementares do processo grupal e que se tornaram também fundamentais na produçáo da identidade do diabético, já que o grupo funcionou como um importante meio de trabalhar as diversas reflexóes advindas dessas vivências e dos ensinamentos advindos do outro.

\section{Reflexão corpórea}

Sobre a segunda categoria intitulada como reflexáo corpórea, entendeu-se que, ao se trabalhar com a prática de yogaterapia, foi possível seguir uma perspectiva de desenvolvimento da consciência corporal, por meio da qual os participantes foram conhecendo melhor seu corpo e suas potencialidades, melhorando também a percepção da respiraçáo, experienciada de forma mais concentrada, atenta, e integrada com o movimento, levando a uma reflexão sobre o próprio corpo. $\mathrm{O}$ que pode ser exemplificado abaixo:

Lívia - Senti a respiração na barriga e dormi até melhor, vou prestando atenção na respiração e relaxo mais profundamente $[. .$.$] eu não tenho mais$ problema com essa ansiedade de não vai dar tempo, não, eu me concentro, eu respiro e dá certo.

Lia - sinto meus pés se movimentarem melhor...

Valéria - "aprendi um tanto de exercício diferente, amei $[. .$.$] senti melhor com as$ práticas $[. .$.$] eu aprendi a respirar aqui,$ durmo muito melhor desde o dia que eu vim a primeira vez...

Esses dizeres ressaltam que houve uma ampliação da capacidade do corpo em executar movimentos, estando essa melhoria relacionada com as articulaçóes. Nesse cenário, também se percebeu mudanças significativas no sentido da sensação de bem-estar, a partir da valorização do indivíduo em sua expressão mais ampla - que contempla seus desejos, suas afliçóes e suas perspectivas diante desse acometimento que exige uma readequação em seu estilo de vida. 
Além da prática de yogaterapia, em uma das OIP, o tema gerador foi a importância dos exercícios físicos para o diabético, ou seja, um dos três pilares de cuidados direcionado a eles. E nessa oportunidade, além do trabalho grupal voltado para o ensinar e aprender, houve um momento em que os participantes puderam aprender alongamentos, exercícios, bem como dançar em grupo, sendo a última uma forma de se exercitar e ter sucesso no tratamento com o diabetes.

José - eu adoro dançar, adorei ter esse momento aqui também...

Roberta - nem sabia que dançar cansava tanto assim, tô suada, queimei muita glicose nessa oficina... (risos).

Maria - se tivesse continuado dançar como fazia antes talvez nem diabetes eu tinha... (risos).

Ao se trazer critérios de inclusão como alternativa de auxílio no tratamento do diabetes, especificamente o pilar de exercício físico, o qual o diabético por vezes não consegue cumprir devido às suas dificuldades físicas ou até mesmo pela inadequação ao seu estilo de vida, deu-se nova forma a esse elemento, já que a partir de então, tornou-se algo prazeroso e descontraído. Assim, pôde-se perceber que a pessoa precisa ter opçóes para escolher e se adaptar, sendo ele o facilitador principal na condução e conservaçáo de seu tratamento.

Diante desse cenário de inclusão, a yogaterapia é um processo que conduz e possibilita o sujeito estar integrado consigo mesmo e com seu corpo, o que é percebido e elaborado mentalmente, que pode ser notado, sentido e interpretado. Essas frases reforçam essa conjuntura:

Lívia - A yoga me ajudou porque antes eu não dava atenção para mim, o que o meu corpo me falava, agora não, consigo ouvir o meu corpo, consigo dar uma resposta pra ele.

Ana - as aulas têm me mostrado possibilidades mais amplas, que não sabia que podia sentir. Tenho me sentido mais leve e animada [...] estou muito 
emocionada, tenho me sentido muito bem com a prática, que trazem bastante entusiasmo e energia.

Por essas falas, pôde-se refletir sobre os benefícios dessa prática, entendendo que mesmo sendo curtos e ligeiros os movimentos, individualizados ou em grupo, a energia constituída nesse processo trouxe percepçóes notáveis capazes de interferir em seu cotidiano e na conduçáo de seu tratamento com o diabetes.

Um fato, a ser abordado nessa esfera, é demonstrado na frase "Xô ferrugem!" (Márcia), uma concepção que se iniciou individual e tomou proporçóes grupais, sendo foco de todos os encontros, como uma maneira simples, singela e mineira de dizer os progressos adquiridos através dessa experiência.

Essa forma de comunicação e manifestação que impulsionou o grupo demonstra sutilmente que a capacidade para ser estimulado, seja mental ou fisicamente, depende somente do desejo do sujeito envolvido no processo. Entendeu-se que ao produzir a percepçáo de um movimento lubrificado, mais fluido, menos tenso, mais destemido e permissível, o acometido se sente empoderado diante de si e de seu grupo, fortalecendo os aspectos de pertença inseridos nesse cenário.

Ao vivenciar e experienciar essas ferramentas de apoio ao acometido pelo diabetes, pôde-se possibilitar a devolutiva dos participantes para a equipe, isso, nos sinais de melhora e alívio das dores crônicas, uma queixa recorrente neste público pesquisado.

Roberta - Não senti a dor na perna que eu sinto todo dia a noite. ( $2^{\circ}$ encontro).

Mariano - Durmo melhor durante a noite, não senti a dor no braço que eu sentia todo dia a noite. ( $4^{\circ}$ encontro).

Maria - eu estou me sentindo bem depois da yoga, meu corpo tá melhor, menos dor... ( $9^{\circ}$ encontro).

Essas frases demonstram que, com as práticas de Yogaterapia, tornouse possível alcançar benefícios, em curto prazo de duração essa terapia proporcionou bem estar, equilíbrio e tranquilidade, além de alívio, 
melhoria e até mesmo o desaparecimento de dores crônicas. Por meio desses relatos, ficou acentuado que esse foi um processo de construção crescente e perceptível para equipe e participantes, nesse contexto.

\section{O processo de elaboração do autocuidado}

Ao construir a terceira categoria, designada como processo de elaboraçáo do autocuidado, foi possível compreender que o cuidado consigo e com sua saúde era ainda para alguns participantes algo inexplorado ou estranho. Assim, o trabalho grupal e as visitas fortaleceram a importância do sujeito diabético para se conhecer e ser detentor de conhecimentos e então conduzir seu tratamento e obter sucesso. O que pode ser observado nos colóquios a seguir:

Antônio - Foi bom pra mim que eu aprendi a controlar o diabetes, antes ela sempre tava acima de 200, agora passei a ficar mais atento [...] comecei a medir (a glicose) mais [...] uma coisa que fui medindo em casa, aqui e aprendendo...

Bruno - se você tem o aparelho pra você medir, você tem que controlar [...] tem dia que eu saio pra caminhar com 200 (glicose), volto já tá baixa aí tenho que repor. Você tem que se autoconhecer.

Maria - não faço extravagância não, se eu não cuidar de mim quem vai né, não tenho ninguém pra cuidar...

Lívia - a gente tem que se conhecer, porque não adianta o médico não vai saber o que a gente vai passar o dia inteiro né!?

Através do processo de grupo nas duas intervençóes e também nos acompanhamentos domiciliares foi nos permitido entender que o escasso conhecimento científico e prático sobre o diabetes, o tempo de acometimento, a idade, a escolaridade e a falta de informação, conduzem os acometidos para um processo de falta de incorporação no cuidado consigo e com sua saúde. O importante papel grupal 
possibilita a troca de informaçóes, entendendo que um acometido esclarecido e sabedor de si e de sua condição de saúde, é considerado além de um facilitador um multiplicador para auxiliar outros acometidos nesta busca por autonomia no tratamento.

Portanto, a educação continuada em diabetes é considerada um caminho construtivo e longo para que o diabético obtenha um espaço de escuta que lhe oferte estímulo pelo conhecimento sobre a sua doença, apoio para sua aceitação e que forneça instrumentos para o autocuidado. Esse fato pode ser observado nesse depoimento:

José - Ajudou a gente a controlar os problemas ne, incentiva [...] controlou muito a minha diabete, as coisas que foi indicado para mim foi muito bom, me ajudou muito, a gente tava meio preocupado, agora quando sobe controlo...

Assim é possível apreender que ao fornecer informação oportuna, apoio de equipe e monitoramento de dados vitais, a autonomia foi sendo acordada nesse processo de mudança de comportamento e de estilo de vida, se defrontando com vigília de si mesmo e com os fatores que a ela se atribuem. A compreensão dessa necessidade, seja de forma isolada, seja em grupo, desperta no sujeito diabético se haver com suas próprias questóes, sendo ele mesmo o detentor do conhecimento e fazedor da mudança.

\section{Relação entre educação e saúde em diabetes}

Iniciando a discussão da última categoria, alcunhada como a relação entre educação e saúde em diabetes, é notório compreender e observar que diversas tentativas têm sido realizadas em nível de mundo no combate da DM, na educação e na prevenção de complicaçóes associadas ao tratamento inadequado, haja vista que sua incidência vem alcançando números assustadores. Nesse sentido, também que se torna de extrema funcionalidade o trabalho nos níveis de atençáo em saúde, isso, no intuito de adequar as propostas de acordo com cada realidade vivenciada pelo sujeito, objetivando melhoria na adesão do acometido. 
Sabe-se que essa não é uma tarefa fácil, pelo contrário, o acometido crônico se vê muitas vezes refugiado diante de si mesmo, com sofrimentos psicossociais, rejeiçóes nos diversos setores, internalização de sentimentos e sensaçóes o que por vezes pode comprometer o seu tratamento, o que pode ser exemplificado nessas frases:

Valéria - Ninguém quer ser doente né!?

Roberta - Falaram comigo que a pessoa que tem diabetes é porque sem vergonha. A gente desanima de cuidar da saúde, sabe?

Lívia - muitas pessoas falam pra mim "não acredito que você gorda desse jeito tem diabetes", acham que eu tenho que ser seca porque como tenho diabetes, eu não posso comer? Eu tenho que comer pra viver né!?

Por esses relatos, compreende-se que, ao se tratar do problema do outro, os indivíduos conseguem expressar seus manifestos de forma mais clara e objetiva, pontuando aquilo que é marcante para si e não para o outro. Esse posicionamento pode estar associado aos aspectos individuais, culturais, sociais e econômicos em que se está inserido.

Por outro lado, pôde-se demonstrar o quanto estar sendo apoiado por profissionais nessa condução para um efetivo tratamento é um fator que contribui não só para pensar nas suas questóes diárias, mas também para buscar melhores condiçôes de vivenciá-las sendo diabético. $\mathrm{O}$ que pode ser observado nos relatos abaixo:

Adriana - Vocês fizeram um bem danado pra nós... Eu descobri o problema da pressão alta e fui no cardiologista e agora tô me cuidando!

Mariano - tem uns 15 anos que descobri que sou diabético e do tipo 1, após a participação no grupo tive uma boa evolução, antes ia três vezes de carro na rua, agora vou somente uma de carro e as outras duas vou a pé, após esta atividade minha glicose melhorou muito, antes 
até para calçar o sapato era ruim a vista escurecia, agora não...

Essas falas demonstram como os participantes viram-se construindo suas estratégias de enfrentamentos diante de suas realidades, isso, nos diversos contextos, nas diferentes maneiras de se gerar os conflitos diários e ainda o modo de lidar com os desafios suscitados nesse caminhar. Estar amparado é contribuir para melhor educação em saúde, melhor adesão, condução e conservação do seu tratamento e constituem elementos relevantes para o planejamento de intervençôes mais efetivas.

\section{CONSIDERAÇÕES FINAIS}

Nesse estudo, como já demarcado anteriormente, o objetivo principal era vivenciar a OY e a OIP como ferramentas complementar e incentivadora para a adesão ao tratamento de acometidos pelo DM na cidade de Tiradentes-MG. Logo, ao final desse projeto, pôde-se concluir que elas podem ser aceitas e utilizadas nessa direção. As consideraçóes que se seguem visam explanar como se chega a esse entendimento.

Primeiramente, quando se objetivou o desenvolvimento de oficinas com esse público, sabia-se da possibilidade de dificuldade de adesão na participação das atividades, pois os acometidos passam por processos que envolvem o comprometimento com sua saúde e a percepção de si no outro, fato que permeia no processo grupal. Porém, observou-se uma adesão significativa do início ao fim de todo o trabalho e essa participação favoreceu as conclusóes desse estudo.

Já os acompanhamentos domiciliares foram aceitos e surtiram efeitos significativos nos participantes. Destaca-se que dos três acometidos que não puderam ser acompanhados, e somente um mostrou-se resistente à adesão da proposta, porém no caso do casal que se mudou de cidade, o esposo se organizou e se inseriu no grupo de intervenção, sendo assíduo em todos os encontros.

Ressalta-se que, inicialmente, a proposta deste estudo seria a comparação dos grupos, porém os acompanhamentos domiciliares nos permitiram entender que náo se criou elementos significativos para 
comparaçóes; se o diabético acompanhado em sua casa e o diabético que participou das intervençóes conseguem ter uma melhor adesão ao tratamento de diabetes ou não. $\mathrm{O}$ fato é que as duas formas de auxiliar e compreender o processo de adesáo advém de um cuidar e estar mais próximo do acometido, independente de qual açáo esteja sendo realizada.

Assim, respondendo aos objetivos deste estudo, torna-se necessário o esclarecimento que pôde-se auxiliar nas atividades de educação e saúde realizadas pela Associação de Diabéticos de Tiradentes, inclusive algumas reunióes foram coordenadas pela equipe do projeto, sendo possível contribuir e observar o processo de relacionamento grupal desses associados. Entendeu-se que é benéfico o trabalho desempenhado por associados, direcionado tanto ao cuidado, ao apoio, aos encaminhamentos e ao fortalecimento grupal estabelecido, além de ser um elo com a rede de saúde. Porém as reunióes não aconteceram por mais de três meses, o que dificultou os resultados propostos nesse estudo, especificamente, no que diz respeito às açôes junto à associação. A fim de atender aos pressupostos estabelecidos nesse estudo as OU e as OIP, tornou-se de extrema relevância abordar as dimensóes reflexivas, corporais e educativas a que estão atreladas. Dessa forma, a vivência experienciada, além de atender ao objetivo geral desse estudo, proporcionou aos participantes aprendizado, autorreflexão e compreensão de suas condutas para o autogerenciamento diante de sua condição de saúde, sendo elas práticas, consideradas ferramentas de auxílio na manutenção e conservação do tratamento.

Assim, os grupos pesquisados foram formados por adultos em idades variadas e com propósitos próximos, em que o cuidado e a conservação do tratamento se tornaram a mola de suas vidas após essas vivências, experiências e acompanhamento.

Notou-se a dificuldade e a complexidade que são atreladas ao diabetes, podendo ser observado que unicamente o modelo biomédico não oferece suporte integral aos acometidos pela doença. Por uma via complementar, acredita-se que açóes como as desempenhadas nas OY e nas OIP puderam ofertar elementos significativos aos participantes.

Foi perceptível, em vários momentos, a falta de conhecimento sobre o diabetes, embora por meio destas ter sido possível refletir sobre as questôes psicossociais e o quanto são influenciadoras no processo do 
cuidar. As alteraçóes nos padrôes de saúde são fortemente refletidas ao se referenciar alguma questáo emocional vivenciada naquela semana ou a permanência de um problema de difícil resolução.

Por meio do trabalho grupal, estabelecido nas OY e OIP, pôde-se refletir sobre a questão do cuidado, o respeito pelo outro em relação à sua saúde, a reflexão corporal e seus benefícios, além de fortalecêlos diante de seus enfrentamentos, uma vez que os participantes partilharam vivências de seus cotidianos.

Outro fato a ser relatado, foi o elo entre a equipe e grupo estabelecido em cada oficina, bem como a troca de conhecimentos e experiências, trazendo confidencialidade e apoio náo somente para debates, mas também para reflexóes coletivas. Portanto, criou-se um espaço de escuta e esclarecimento de dúvidas no intuito dos acometidos refletirem sobre a necessidade de enxergar a sua realidade e conviver com o diabetes, mesmo tendo percalços a serem enfrentados diariamente. Para eles, suas residências se tornaram espaços de expressão de sentimentos e anseios, monitoramento de sua saúde, dúvidas e crenças atreladas ao diabetes, além de ser reconhecido pelos participantes como um momento de se conhecer e se autocuidar, sendo estabelecidos os vínculos de cumplicidade e confidencialidade.

Compreendeu-se que os aspectos emocionais são para esses diabéticos uma válvula para desencadear os picos de hiperglicemia, uma vez que, ansiedade, estresse, tristeza e preocupaçóes diárias, sáo aspectos que estiveram presentes nos encontros. Porém, vale ressaltar que não existe diabetes emocional, mas sim situaçóes emocionais que interferem na produção e sintetização da insulina.

Em relaçáo aos àsanas e prayanas trabalhados, pode-se perceber que proporcionaram melhor capacidade física, flexibilidade, clareza mental, possibilidade de respirar melhor, estimulou os sentimentos e pensamentos, trouxe vigor mental e aumentou a percepção do corpo, da mente e dos sentimentos.

As OIP foram trabalhadas seguindo os pilares de cuidados no diabetes, sendo eles: dieta, medicação, insulinoterapia e exercícios físicos. Percebeu-se que não importa o tempo de diagnóstico, a alimentação é o pilar de tratamento considerado de maior dificuldade e cumprimento para esses participantes. É possível argumentar que a 
intervenção psicossocial, utilizando estratégias de abordagem face a face e individual, pode ter contribuído para a melhora do autocuidado com o DM, em detrimento do conhecimento, por engajar mais a prática do usuário no seu dia a dia.

Assim, nos acompanhamentos realizados pela enfermagem, como verificação de pressão arterial/glicemia capilar/frequência cardíaca e saturação de $\mathrm{O}_{2}$, medida de circunferência abdominal e cálculo de IMC, pôde-se constatar que náo foram encontrados dados de alteração significativa em todos os índices verificados, isso em uma perspectiva de tendência, seja de modo positivo ou negativo. Perceberam-se alteraçóes pontuais em participantes, mas sem elementos consistentes que possam indicar mudanças significativas.

Como retorno dessas açóes obteve-se a devolutiva de retomada de caminhadas, busca por atendimento médico especializado, melhor cuidado com a alimentaçáo e com os remédios, ensinamentos e aprendizados mútuos, além da busca pelo autocuidado, autonomia e autogerenciamento de sua condição de saúde, o diabetes.

Diante das categorias estabelecidas neste estudo - reflexão psicossocial, reflexão corpórea, processo de elaboração do autocuidado e a relação entre educação e saúde em diabetes -, percebeu-se que esse público está ligado por esses elos de percepção, em que o apoio profissional se tornou extremamente necessário não somente para escutá-los em suas demandas biomédicas, mas também nas psicossociais. Ao se conhecer e conhecer seu próprio corpo, o diabético se vê empoderado diante de si e dos outros, conseguindo construir autonomia diante de suas demandas e enfrentamentos. $\mathrm{O}$ processo de se cuidar para o público pesquisado, ainda está em elaboraçáo e sendo construído diariamente, sendo dependente do contexto que estão inseridos associado a forma cultural de construção de conhecimento de cada sujeito. E em relação à educação em diabetes, é de extrema importância a continuidade deste trabalho, uma vez que, o diabético necessita de auxílio na conservação e adesão ao tratamento.

Compreendeu-se que os comportamentos e as práticas de educação em saúde para o diabetes vêm se tornando imprescindíveis diante do contexto atual. Não se tratando aqui, somente de números, mas de situaçóes vivenciadas, experienciadas e relatadas, nas quais a realidade do ser diabético, ora está voltada para práticas cotidianas 
e corriqueiras, ora para práticas tradicionais, ora para erros e acertos em seu tratamento e na condução do mesmo. Essas ações abrangeram variados aspectos a que os sujeitos estão inseridos, possibilitando criar ferramentas educativas a fim de facilitar a expressão de sentimentos, produção de aprendizado, além de permitir que os sujeitos se descubram e criem novas formas de enfrentamento diante da vida.

Para tanto, em uma cidade com pouco mais de 7.000 habitantes, para além da manutenção do suporte básico de saúde, a realidade de vida dos diabéticos necessita, ainda, de programas para a educação continuada em diabetes, no intuito de melhorar adesão ao tratamento e promover a qualidade de vida. Sabe-se que os programas voltados para a educação continuada são capazes de desenvolver habilidades específicas naqueles e incorporar ferramentas necessárias para a eficiência e a eficácia no tratamento. Além disso, esse grupo se tornou mais esclarecido e orientado, fato que alivia a sobrecarga do sistema de saúde, advinda do mau controle do diabetes.

Nesse sentido, o papel da Estratégia Saúde da Família é de fundamental importância, uma vez que, pode ser contínuo e próximo, fortalecendo as bases já solidificadas no projeto de extensão e expressadas nesses relatos, em que os sentimentos de desproteção e carência de aporte profissional estiveram presentes.

É sabido que esse estudo não possui em sua proposta o cabedal para a generalização dos elementos construídos, especificamente, por sua duração reduzida e pela necessidade de um trabalho desta natureza por um período significativo de acompanhamento. Logo, indica-se como proposta futura, a continuidade do mesmo ou, da execução de estudos desta ordem por um período mais extenso.

\section{REFERÊNCIAS}

AFONSO, M. L. M. (org). Oficinas em dinâmica de grupo na área da saúde. São Paulo: Casa do Psicólogo, 2006.

AFONSO, M. L. M. Notas sobre sujeito e autonomia na intervenção psicossocial. Psicologia em Revista, Belo Horizonte, v. 17, p. 445464, 2011. 
AFONSO, M. L. M; FADUL, F. M. O trabalho com grupos no PAIF: um diálogo interdisciplinar com a oficina de intervenção psicossocial. Pesquisas e Práticas Psicossociais, São João Del Rei, v. 10, n. 1, p. 140-154, 2015.

APDP - ASSOCIAÇÃO PROTETORA DOS DIABÉTICOS DE PORTUGAL. 2015. Sintomas de hipoglicemia. Disponível em: http://www.apdp.pt/diabetes/a-pessoa-com-diabetes/sintomas. Acesso em: 16 nov, 2018.

BERNARDI, M. L. D. et al. Efeitos da intervenção hatha-yoga nos níveis de estresse e ansiedade em mulheres mastectomizadas. Ciênc. Saúde Coletiva, Rio de Janeiro, v. 18, n. 12, p. 3.621-3.632, 2013 Doi: $10.1590 / S 1413-81232013001200018$.

BRANDHA, M.; SARASWATI, S. Asana Pranayama Mudra Bandra. Bihar: Yoga Publication Trust, 2009.

BRASIL. Ministério da Saúde. Estratégias para o cuidado da pessoa com doença crônica: diabetes Mellitus. Brasília: Ministério da Saúde, 2013. (Cadernos de Atenção Básica, n. 36). Disponível em: http:// bvsms.saude.gov.br/bvs/publicacoes/estrategias_cuidado_pessoa_ diabetes_Mellitus_cab36.pdf. Acesso em: 18 nov. 2018.

FREIRE, P. Pedagogia da autonomia: saberes necessários à prática educativa. São Paulo: Editora Paz e Terra, 1996.

HERMÓGENES, J. Autoperfeição com hatha yoga. 61. ed., Rio de Janeiro: Best Seller, 2014.

IDF - INTERNATIONAL DIABETES FEDERATION. IDF Diabetes Atlas. 2015. Disponível em: http://www.diabetesatlas.org/. Acesso em: 18 nov, 2018.

IYENGAR, B. K. S. Luz sobre o yoga. São Paulo: Pensamento, 2016.

MCCALL, T. Yoga as medicine: the yogic prescription for health and healing. New York: Bantam Books, 2007.

MENEZES, K. K. P.; AVELINO, P. R. Grupos operativos na Atenção Primária à Saúde como prática de discussão e educação: uma revisão. 
Cad. Saúde Colet., Rio de Janeiro, v. 24, n.1, p. 124-130, 2016.

OLIVEIRA, J. E. P.; MONTENEGRO JUNIOR, R. M.; VENCIO S. Diretrizes da Sociedade Brasileira de Diabetes 2017-2018. São Paulo: Clannad, 2018.

OLIVEIRA, E. V. M. de et al. Compreendendo a diabetes Mellitus na adolescência: açóes de um trabalho grupal. In: OLIVEIRA, A. L. de; RUFINO, J. de A.; SILVA, M. C. da (org.). Saberes e fazeres: coletânea de artigos de extensão e de pesquisa do IF Sudeste-MG Campus São João del-Rei. São João del-Rei: IFMG, 2016. p. 48-61.

REZENDE, D. P. Doce vida/associaçáo dos portadores de diabetes de Sáo Joáo del-Rei: um estudo de caso sobre a atenção psicossocial e a adesão ao tratamento em diabetes. São João Del Rei. 124 f. 2017. Dissertação (Mestrado em Psicologia) - Universidade Federal de São João del-Rei, São João del-Rei, 2017.

Submetido em 27 de dezembro de 2018.

Aprovado em 23 de janeiro de 2019. 